\title{
Actitudes populistas y percepciones de la opinión pública y los medios de comunicación: Estudio correlacional comparado entre España y Colombia
}

\section{Populist attitudes and perceptions of public opinion and the media: A comparative correlational study between Spain and Colombia}

Luis M. Romero-Rodríguez. Universidad Rey Juan Carlos. España. ESAI Business School, Universidad Espíritu Santo. Ecuador.

luis.romero@urjc.es

$[\mathrm{CV}]\left(\mathrm{G} \mathrm{R}^{\mathrm{C}} \mathrm{O} \%\right.$

Santiago Tejedor. Universidad Autónoma de Barcelona. España.

santiago.tejedor@uab.cat

$[\underline{\mathrm{CV}}]$ (c) $\mathrm{R}: 0$

María Victoria Pabón Montealegre. Universidad Pontificia Bolivariana. Colombia. maria.pabon@upb.edu.co

\section{$[\mathrm{CV}] \odot \mathrm{G}$}

Este trabajo está avalado por el Proyecto I+D+I (2019-2021), titulado "Youtubers e Instagramers: La competencia mediática en los prosumidores emergentes" con clave RTI2018-093303-B-I00, financiado por Ministerio de Ciencia, Innovación y Universidades de España y el Fondo Europeo de Desarrollo Regional (FEDER) y por el Proyecto I+D-i (2020-2022), titulado "Instagramers y youtubers para el empoderamiento transmedia de la ciudadanía andaluza. La competencia mediática de los instatubers", con clave P18-RT-756, financiado por la Junta de Andalucía, en la convocatoria 2018 (Plan Andaluz de Investigación, Desarrollo e Innovación, 2020) y el Fondo Europeo de Desarrollo Regional (FEDER).

Cómo citar este artículo / Referencia normalizada

Romero-Rodríguez, L.M., Tejedor, S., y Pabón Montealegre, M.V. (2021). Actitudes populistas y percepciones de la opinión pública y los medios de comunicación: Estudio correlacional comparado entre España y Colombia. Revista Latina de Comunicación Social, 79, 43-66. https://www.doi.org/10.4185/RLCS-2021-1507

\section{RESUMEN}

Introducción: El populismo ha experimentado un crecimiento preocupante en la última década en diferentes enclaves del planeta. Este proceso, de cariz globalizador, se ha visto potenciado por las características de inmediatez, interacción y participación de las redes sociales, los cibermedios y otras plataformas digitales. En este contexto, la percepción que la juventud confiere a este tipo de fenómenos constituye un campo de estudio de gran interés para las Ciencias Sociales. Esta investigación examina las correlaciones entre las actitudes populistas, la percepción de la opinión pública y las opiniones sobre los medios de comunicación en estudiantes de Ciencias de la 
Comunicación de Colombia y España. Metodología: A partir de un enfoque exploratoriocorrelacional y un diseño cuantitativo, la presente investigación ha analizado las reflexiones y las prioridades de un grupo de $n=499$ estudiantes de grados y postgrados afines a Ciencias de la Comunicación de Colombia y España. Resultados: El estudio ha corroborado el papel protagónico que desempeñan las redes sociales en la formación de opiniones radicales, al tiempo que se detecta una caída del influjo de la televisión entre el público joven. Además, el trabajo establece que el índice de percepción de la opinión pública resulta mayor en España, mientras que el de percepción mediática o el de actitudes anti-elitistas son superiores en Colombia, y no se evidencia una clara articulación entre las actitudes populistas y una ideología política de extremos. Conclusiones: Las correlaciones examinadas constatan una tendencia al desapego y descrédito hacia la política en general, en especial por la población joven, que afecta a los actores y a las instituciones. Alude a la preferencia de este grupo poblacional por interactuar e informarse en las plataformas digitales y presenta actitudes populistas, sin clara identificación ideológica, pero con una clara tendencia hacia la simplificación de los mensajes, por lo que se enfatiza en la necesidad de educar la mirada crítica de la ciudadanía y de trabajar en la media literacy como una estrategia crucial frente al crecimiento y expansión del populismo.

PALABRAS CLAVE: Opinión pública; comunicación política; persuasión; medios sociales; periodismo.

\begin{abstract}
Introduction: Populism has experienced a worrying growth in the last decade in different locations around the world. This globalizing process has been enhanced by the immediacy, interaction and participation of social networks, cybermedia and other digital platforms. In this context, the perception that young people give to this type of phenomena constitutes a field of study of great interest for the Social Sciences. This research examines the correlations between populist attitudes, perception of public opinion and opinions about the media in students of Communication Sciences in Colombia and Spain. Methods: Based on an exploratory-correlational approach and a quantitative design, this research has analyzed the reflections and priorities of a group of $n=499$ undergraduate and graduate students related to Communication Sciences in Colombia and Spain. Results: The study has confirmed the leading role played by social networks in the formation of radical opinions, while detecting a decline in the influence of television among young audiences. In addition, the study establishes that the index of public opinion perception is higher in Spain, while the index of media perception or anti-elitist attitudes is higher in Colombia, and there is no clear link between populist attitudes and a political ideology of extremes. Conclusions: The correlations examined note a tendency towards disaffection and discredit towards politics in general, especially by the young population, which affects actors and institutions. It alludes to the preference of this population group for interacting and informing themselves on digital platforms and presents populist attitudes, without clear ideological identification, but with a clear tendency towards simplification of messages, thus emphasizing the need to educate the critical view of citizens and to work on media literacy as a crucial strategy against the growth and expansion of populism.
\end{abstract}

KEYWORDS: Public opinion; political communication; persuasion; social media; journalism.

\title{
CONTENIDO
}

1. Introducción. 1.1. Política y comunicación. 1.2. La polarización en la comunicación política. 1.3. El populismo y la polarización. 1.4. El contexto español. 1.5. El contexto colombiano. 2. Materiales y método. 2.1. Instrumento. 2.2. Participantes. 2.3. Procedimiento. 3. Resultados. 3.1. Valores generales. 3.2. Diferencias por país. 3.3. Diferencias sociodemográficas. 3.4. Diferencias políticas. 3.5. Correlaciones entre índices. 3.6. Modelo de regresión. 4. Discusión. 5. Conclusiones. 6. Referencias. 


\section{Introducción}

El incremento de la actividad en las redes sociales, especialmente en el público joven, ha venido acompañado de una eclosión de mensajes populistas y de manifestaciones de odio (Badjatiya et al., 2017). Por ejemplo, Valdez et al. (2019) han evidenciado que el $72 \%$ de las publicaciones en español en Twitter sobre personas desplazadas posee un tono negativo y representa a ese colectivo como una amenaza. En el ámbito del populismo, Castilla (2020) identifica que los ataques a la élite son frecuentes en la estrategia comunicativa de diversos partidos políticos, si bien detecta diferencias en la concepción de este grupo social, así como respecto a la frecuencia y la utilización de dichas críticas. Asimismo, del Pino y Goenechea Permisán (2020) y Romero-Rodríguez, Contreras-Pulido y Pérez-Rodríguez (2019) advierten que los jóvenes están hiperexpuestos a mensajes populistas y de odio, pero no disponen de estrategias ni competencias suficientes para afrontarlos.

El concepto de populismo, si bien no es de nueva data, ha sido objeto de numerosos abordajes teóricos en los últimos años. Laclau (citado por Gutiérrez, 2011) y Espí (2019) lo conciben como un conjunto de corrientes políticas heterogéneas que movilizan a un gran número de personas a partir de la utilización de contenidos emocionales que, especialmente, aluden a la identidad y la autoafirmación como pueblo (Cervi y Tejedor, 2021). El auge y la popularización de las redes sociales y de las múltiples plataformas digitales han impactado en el alcance de este tipo de mensajes, al tiempo que demandan de nuevos estudios sobre la concepción que los jóvenes poseen de estos aspectos y cómo interaccionan con estos asuntos.

El consumo de la información se ha convertido en una experiencia social (Tejedor et al., 2018), mientras que los contenidos informativos se han transformado en piezas portátiles, personalizadas y participativas (Matsa y Mitchell, 2014). Autores como Shao (2009), Sheldon (2009), Quan-Hasse, A. y Young (2010), Papacharissi y Mendelson (2011), Lin y Lu (2011), Cheung et al. (2011), Baek et al. (2011) o Ruano et al. (2016), entre otros, han destacado la importancia que los jóvenes confieren a las redes sociales para crear vínculos con usuarios con intereses afines (homofilia). Diversos estudios han incidido en la facilidad para compartir los contenidos con otros internautas (Alhabash et al., 2012; Sharma y Verma, 2015; Chung et al., 2016), el fácil acceso a numerosos recursos y cuentas (Martínez y Ferraz, 2016), y la autonomía para definir una dieta informativa propia (Kurtulus y Ozkan, 2015). Son, en definitiva, características atribuibles a las redes sociales y a las dinámicas que promueve entre sus usuarios (Yang et al., 2019).

Las redes sociales, teniendo en consideración la atención flotante de los usuarios (Liu et al.; 2018), apuestan por contenidos que destacan por su brevedad, dinamismo, musicalización y uso de colores y recursos visuales de impacto (Lin et al., 2017), consolidándose estas como un objeto de estudio constantemente vinculado con los jóvenes. Piscitelli (2010), Colás et al. (2013), Bernal y Angulo (2013) y Pérez Tornero et al. (2015), entre otros, han advertido acerca de la preferencia de los jóvenes por este tipo de plataformas; llegando incluso a abandonar otros espacios informativos por la atracción de la comunicación instantánea que potencian las redes (Schwarz, 2011). La llamada «generación $Z$ » o centennials, que agrupa a los nacidos desde finales de la década de los 90 hasta 2012, ha inaugurado nuevas líneas de investigación en el campo de las redes sociales (Manzanares, 2020).

\subsection{Política y comunicación}


En el ejercicio natural y cotidiano de un sistema político democrático es imprescindible la comunicación. La política implica un intercambio de ideas entre las personas de un grupo, donde unos convencen a otros de las medidas que se deben tomar para conseguir el «bien común». En este sentido, Canel (1999) destaca la importancia de la comunicación. La toma de decisiones necesita de la información y del intercambio de opiniones entre quienes intervienen, ayuda a que las medidas sean vinculantes dentro de la comunidad, y permite organizar a la sociedad porque fija objetivos, resuelve conflictos y legitima las acciones. Esa fusión de propósitos, conocimientos y técnicas deriva en la comunicación política y persigue mejorar las relaciones entre los gobernantes y gobernados, candidatos y electores, fortalecer fenómenos de liderazgo y poder en la función pública e incrementar la influencia social (Reyes et al., 2011).

En los orígenes de la democracia, el poder se ejercía de forma anónima y destacaban las ideologías. A finales del siglo XX, esta dinámica se personalizó cada vez más, dando paso a lo que Dader (1990) denominó la «vedetización» de los políticos y la creación de un «Estado-espectáculo», en el que los políticos y los públicos buscaban esa personalización para reflexionar, evadirse o identificarse de manera sencilla, debido a que resulta más fácil y natural sentir simpatía por una persona que por una ideología. Bajo la perspectiva de que el mundo de las ideas es abstracto e implica un raciocinio, se trabajó con la figura del dirigente que mueve emociones. A esto se sumó el fortalecimiento de los medios como intermediarios. Este proceso incrementó la pasividad de las audiencias para entender y aprehender lo que pasa en sus sociedades.

Según el mismo Dader (1990), esa personalización de la política trajo la «condensación de imágenes», porque los argumentos y acciones políticas se redujeron a personajes creados. De esta forma se configuraba una estructura dramática en la que el resto de los ciudadanos, que deberían tener participación, pasaban a ser simples espectadores. Se llegó a tal punto en la retórica política que el protagonismo político de un partido y su ideología se concentró totalmente en la presencia de un líder carismático. El ascenso de los medios masivos de comunicación disminuyó el activismo político (Maarek, 1997), "puesto que la participación directa en un partido ya no conlleva ningún tipo de gratificación, ni siquiera psicológica, si se compara con la posición de un simple simpatizante o votante, ¿por qué molestarse en ser voluntario?” (op. cit., p.236). En esta línea, Carey (1999) argumenta que, en la historia de las relaciones entre medios y democracia, en las últimas décadas del siglo pasado se observaba un sistema de «democracia sin ciudadanos», otorgándole a los medios gran protagonismo de este fenómeno.

En las interacciones de los políticos con los medios de comunicación, históricamente los primeros se han valido de las técnicas y estrategias de marketing buscando crear artificialmente una redundancia en el mensaje por medio de una aceleración del efecto agenda setting. Maarek (1997) destaca que los medios aportaron el conocimiento que tenían de las audiencias seleccionadas como objetivos, y de saber las formas de ocio de los espectadores para dirigirse a ellos, no solo por medio de periódicos que leían por motivos de trabajo, sino también a través de revistas y otros medios que usaban por entretenimiento. La gestión de contenidos se segmentó por perfiles y grupos de audiencias hasta el surgimiento de Internet, que aceleró la co-producción y distribución de información:

En los sistemas comerciales, la creciente «nichificación»de las audiencias de medios fue apoyada y alentada por el mercado publicitario interesado en apuntar a cortes de consumidores cada vez más especializados y diferenciados, según variables sociales y parámetros de consumo (Turow, 1997). Internet fue la culminación de este proceso de fragmentación de públicos al facilitar la proliferación de contenidos y el relativamente fácil acceso a la producción y distribución de contenidos (Waisbord, 2020, p.257). 
Según varios autores, como Sadiki (2018), Lazer et al. (2018), Nyilasy (2019), y Waisbord (2020), la comunicación política en la actualidad resulta más mediatizada y fragmentada ante la diversidad de opciones, comparada con la era moderna de los medios masivos, cuando las opciones eran más limitadas. Para Waisbord (2020), dicha partición mediática ofrece contenidos que pueden ajustarse a intereses e identidades políticas particulares, pero termina fracturando el diálogo político y social porque refuerza simpatías, diferencias y odios.

El uso creciente de las redes sociales ha provocado que los medios convencionales perdieran el oligopolio que ostentaban en la selección, tratamiento y jerarquización de lo que es noticia y de cómo se presentan y difunden ante las audiencias (Catalina-García et al.,2019; Rodríguez-Hidalgo et al., 2020). El ciudadano se convirtió en medio, productor y consumidor de información y se muestra confundido ante la cantidad de información que recibe en el ecosistema digital (Romero-Rodríguez y Mancinas-Chávez, 2016).

\subsection{La polarización en la comunicación política}

El ejercicio político contemporáneo se caracteriza por la polarización, entendida como la identificación de dos perspectivas que se manifiestan en una división social entre extremos antagónicos, rígidos en sus posiciones, que exigen adscripción a solo uno de ellos (Blanco y De la Corte, 2003). Esa fragmentación implica una tensión permanente pues "el acercamiento e identificación con un polo supone alejamiento y total rechazo de la postura contraria y de las personas que la defienden en términos conceptuales, afectivos y comportamentales" (Villa Gómez et al., 2020, p.19).

Son diversos los factores que intervienen para que se dé la polarización. De acuerdo con Waisbord (2020), las élites políticas se sitúan en posiciones extremas y no presentan motivos para la negociación y el consenso, de tal manera que fomentan la división en la ciudadanía a través de temas que movilizan. Esta actitud propicia una mayor polarización en la ciudadanía que, a su vez, sustenta las decisiones y posturas de las élites. Por su parte, según Romero-Rodríguez et al. (2015) y Civila et al. (2020), la polarización es el resultado de la exacerbación del discurso demonizador en contra de la otredad, maximizado por los medios de comunicación y las redes sociales, en función de ofrecer un «espectáculo» fundamentado en el conflicto (Cervi y Tejedor, 2020).

Tal y como se extrae de lo anterior, el periodismo y los medios de comunicación convencionales también aportan a la polarización porque, en la mayoría de los casos, no mantienen la relativa imparcialidad y el terreno neutral que la ética informativa impone. Medios comerciales y públicos terminan tomando alguna posición partidista, dejándose permear por prácticas de relaciones públicas (como los publirreportajes y los advertorials de los partidos políticos), agentes de información política, portavoces políticos y equipos de publicidad y propaganda de diversas instituciones no lucrativas (Catalina-García et al., 2019). Esto además se ve profundizado por las prácticas aceleradas del periodismo actual que intenta competir en términos de igualdad con la ubicuidad e inmediatez de los contenidos de las redes sociales (Romero-Rodríguez, Tejedor y Castillo-Abdul, 2021).

Aunado a lo anterior, el uso del algoritmo de los medios sociales refuerza estas actitudes antagónicas (Waisbord, 2020), en las que no se reconoce y escucha a quien opina diferente, sino que hace imperar a la homofilia, pues el algoritmo apunta a generar contenidos a la medida de los intereses y afinidades de las personas, pero termina por crear «burbujas filtro», término acuñado por Pariser (2011), que se entiende como los espacios digitales "que mantienen a la ciudadanía en mundos relativamente cerrados ideológicamente, sin apertura a visiones diferentes, lo que refuerza aún más los sesgos confirmatorios. Las burbujas supuestamente operan como distribuidores de agrupamientos 
sociopolíticos; son separadoras de personas que refuerzan ideas negativas y hostiles frente a otros" (Waisbord, 2020, p 14). Dentro de las «burbujas filtro» los usuarios ven lo que los diferentes sistemas tecnológicos concluyen que quieren ver, y no lo que tienen que ver (Rossi, 2018), resultando un sesgo tecnológico en el que los usuarios no deciden lo que se les muestra y desconocen el mundo que queda afuera.

\subsection{El populismo y la polarización}

La polarización dificulta el consenso necesario para el ejercicio democrático porque se sustenta en el conflicto y la tensión. Desde esta perspectiva, se explica que, en un ambiente de polarización, en el que prevalece el descontento de la gente y la inequidad y exclusión de minorías, se desarrolle el populismo.

Para Waisbord (2018), el populismo ofrece una visión rígida de la política entre dos actores enemigos: el pueblo contra las élites, pudiendo ser estas últimas la oligarquía, el imperialismo, los medios de comunicación o las empresas extranjeras, en antagonismo con el pueblo y el líder carismático y demagógico que busca acabar -simbólicamente o no- con toda forma de control elitista y con la oposición. Obviamente, la noción de «pueblo cohesionado» no se refiere en esta simplificación conceptual a su definición purista del conjunto de ciudadanos que hacen vida en un contexto determinado, sino a los seguidores o adeptos del emisor discursivo, lo que significa que todo lo que no se circunscriba a dichas características es una «otredad» política.

Mudde y Rovira (2019) sostienen que el populismo no se caracteriza por una ideología fundante, sino que se nutre de otras ideologías, por lo que se pueden dar tanto populismos de derechas como de izquierdas, populismos conservadores y liberales, que se soportan en asuntos con gran significado para el pueblo o las mayorías, tales como devolverles la dignidad, el reconocimiento y lo que les corresponde a partir de la soberanía, la movilización social y el partido político, y señalar a las élites como corruptas y causantes de todos los males.

En la articulación del populismo contemporáneo con la comunicación, Waisbord (2018) destaca que la fragmentada ecología informativa de medios tradicionales y digitales permitió consolidar a las figuras mesiánicas que buscan deslegitimar a otros grupos de poder e instituciones y atraer simpatizantes.

\subsection{El contexto español}

El sondeo Jóvenes, Participación y Cultura Política del Instituto de la Juventud (2017) pone de manifiesto que los jóvenes entre 15 y 29 años están cada vez más interesados por la política en España: un 37\% declara sentir mucho o bastante interés. En este sentido, la política es cada vez más un tema de conversación entre los jóvenes y sus familias (63\%), amistades (50 \%) y compañeros de trabajo o estudios $(40 \%)$.

La desconfianza en los partidos y representantes políticos que manifiestan muchos jóvenes es ligeramente más acusada entre los simpatizantes de nuevos partidos como Podemos (54 \%) y Ciudadanos (51\%), que entre los seguidores de partidos tradicionales como el PP (35\%) y el PSOE $(47 \%)$. También existe una mayor diferencia entre aquellos jóvenes que se ubican ideológicamente en la izquierda moderada, los estudiantes (51\%), los jóvenes de clase media/baja y baja (50 \%), y entre quienes declaran mostrar poco interés por la política (56 \%). Esto refleja el hecho de que uno de cada tres jóvenes (35\%) no siente cercanía hacia ningún partido (Injuve, 2017). 
El estudio IAB Redes Sociales 2020, establece que en España el $87 \%$ de los internautas de 16 a 65 años (alrededor de 26 millones de usuarios) usa redes sociales. El perfil del usuario español de redes sociales se sitúa en una edad promedio de 40 años y es muy similar en ambos sexos: un $49 \%$ son hombres y un $51 \%$ mujeres. El informe señala que cada usuario utiliza una media de 4,5 redes. Las redes más usadas son Whatsapp (85 \%), Facebook (81 \%), e Instagram (59 \%) (IAB, 2020). En concatenación con lo anterior, Gómez de Travesedo-Rojas, y Gil (2020), señalan que los jóvenes están interesados por los temas políticos y que sus medios preferidos para informarse de estos temas son la televisión, las páginas de internet y las redes sociales. Para 2020, Vox es la fuerza política con más seguidores en las redes sociales vinculadas con el público joven (Tik Tok, Youtube e Instagram), mientras que pierde protagonismo en Facebook y Twitter (Rodríguez-Rata, 2020).

\subsection{El contexto colombiano}

En la historia política de Colombia prevalece una tradición de confrontación y construcción del opositor como enemigo, que facilita el desarrollo de la polarización. Esto se evidencia en las guerras civiles del siglo XIX, en los enfrentamientos entre liberales y conservadores en la primera mitad del siglo XX y el posterior periodo de violencia que dejó un saldo de 250 mil muertos entre 1946 y 1957 y más de dos millones de desplazados (Molano, 1985). En 1958 se instaura una coalición bipartidista, denominada «Frente Nacional», que funcionó hasta 1974, y que generó otro capítulo en la violencia del país, protagonizado por las guerrillas revolucionarias y el paramilitarismo. Varios intentos de gobiernos posteriores de buscar una salida negociada al conflicto terminaron en fracasos y en reforzar la salida militar para dar soluciones a los problemas del país (Villas et al., 2020).

Durante el gobierno del presidente Juan Manuel Santos, se encaminaron los esfuerzos a lograr una negociación para configurar un tratado de paz con las Fuerzas Armadas Revolucionarias de Colombia- Ejército del Pueblo (FARC-EP). Los diálogos se iniciaron en el 2012 y se extendieron hasta la firma del acuerdo de paz el 26 de septiembre de 2016, en la ciudad de Cartagena. En ese tiempo se mantuvo a los ciudadanos apartados de las discusiones que se llevaban a cabo en la mesa de negociación. Pero luego de la firma del Acuerdo de Paz, el gobierno optó por refrendarlo con un plebiscito en el que los ciudadanos debían votar por el Sí (si apoyaban la firma del acuerdo) o NO (si estaban en contra del acuerdo). Durante el proceso de socialización de los puntos del acuerdo y en la convocatoria al plebiscito se evidenció un incremento en la polarización del discurso político, entre extremos: Los del SI, que se autodefinían por estar "a favor de la paz", seguidores del gobierno de Santos, y quienes estaban en contra "de negociar una paz con terroristas", seguidores del expresidente Álvaro Uribe. Los resultados de la consulta le dieron la mayoría al NO. La comunicación política en los siguientes procesos electorales ha mantenido la misma polarización, en extremos que hoy se definen como la derecha, para los seguidores del presidente Uribe y para el resto, se suelen identificar como de Izquierda o independientes, denominación que asume cualquier candidato que se erija como opositor a la tendencia uribista.

De acuerdo a un reciente estudio de la Dirección Nacional de Estadística, [DANE], 2020, se estima que Colombia cuenta con una población de 10.990.268 jóvenes de 14 a 26 años que representan el $21,8 \%$ de la población total. Sobre la participación política de los jóvenes en este país, de acuerdo a este informe, la población entre 18 y 25 años tuvo la menor participación en las últimas elecciones presidenciales del país, realizadas en el 2018, comparados con los demás grupos de edad. 43,8\% de este grupo poblacional no votó. Entre las principales causas por las cuales no sufragó se destacan: Le faltó inscribir la cédula (38,3\%); Desinterés $(32 \%)$; Los candidatos prometen y no cumplen $(26,1 \%)$ y Los políticos son corruptos $(24,6 \%)$. 
En la misma encuesta, se indagó por la posición ideológica asociada al rango de edad. En el grupo de los jóvenes el 41,3\% se identificó con la opción del Centro; un 23,9\% No sabe / no informa; un $19,1 \%$ eligió la Derecha y un 15,7\% la Izquierda. Sobre la forma cómo se informan de los asuntos políticos, un 96,5\% usa fuentes validadas (televisión, radio, revistas o periódicos, internet y libros); mientras que un $85 \%$ utiliza fuentes no validadas como las redes sociales, conversaciones con otras personas y promoción de mensajes en espacio públicos.

El objetivo principal de la presente investigación es examinar las correlaciones entre las actitudes populistas, la percepción de la opinión pública y las opiniones sobre los medios de comunicación en estudiantes de Ciencias de la Comunicación de Colombia y España, partiendo de las siguientes hipótesis $(h)$ :

h1: Mientras las actitudes populistas de una persona se hacen más fuertes, percibirá mayor congruencia de la opinión pública sobre sus propias opiniones.

h2: Cuando las actitudes populistas de una persona se fortalecen, se perciben las informaciones de los medios de comunicación como incongruentes con sus puntos de vista.

h3: Mientras incrementan las actitudes populistas de una persona, la diferencia entre congruencia de la opinión pública y de la hostilidad de los medios de comunicación aumenta.

\section{Materiales y método}

El presente estudio es de alcance exploratorio y de diseño cuantitativo, en la medida de que intenta aproximarse al fenómeno de estudio de forma primigenia para descubrir nuevos conocimientos, sin recurrir a inferencias estadísticas sobre la totalidad de los universos de ambos contextos en estudio. Lejos de buscar ser explicativo, el enfoque será descriptivo-correlacional, pues el objetivo de la investigación es analizar las interrelaciones que existen entre las actitudes populistas, la percepción de la opinión pública y las opiniones sobre los medios de comunicación.

\subsection{Instrumento}

Se realizó una adaptación del instrumento de Schultz, Wirth y Müller (2020), contentivo de 26 ítems, de los cuales 5 eran relativos a variables independientes (país, edad, sexo, nivel educativo y medio o plataforma que utiliza para informarse), mientras que el resto estaban relacionados con las hipótesis del estudio, a saber: 
Tabla 1. Dimensiones del estudio con validación de constructo y contenido interjueces.

\begin{tabular}{|c|c|c|}
\hline & $\begin{array}{c}\text { Valor } \\
\text { interjueces } \\
(\square)\end{array}$ & $\begin{array}{c}\text { Kappa de } \\
\text { Cohen } \\
(k)\end{array}$ \\
\hline \multicolumn{3}{|l|}{ Percepciones políticas } \\
\hline En una escala del 1 al 5 ¿Qué tan interesado estás en la política? & 4.00 & .750 \\
\hline $\begin{array}{l}\text { En política a veces se habla de ser de "izquierdas" o de "derechas" ¿En dónde } \\
\text { te ubicarías? }(*)\end{array}$ & 3.50 & .700 \\
\hline \multicolumn{3}{|l|}{ Percepciones de opinión pública } \\
\hline $\begin{array}{l}\text { Mi opinión acerca de la política en mi país es similar a muchas de las } \\
\text { opiniones de aquellos que me rodean y que sigo en las redes sociales }\end{array}$ & 4.25 & .800 \\
\hline $\begin{array}{l}\text { En la ciudad donde vivo, la mayoría de las personas piensan sobre la política } \\
\text { de mi país de la misma forma que yo }\end{array}$ & 4.50 & .800 \\
\hline $\begin{array}{l}\text { La mayoría de las personas de mi país opinan de la política de la misma } \\
\text { forma que yo }\end{array}$ & 4.75 & .825 \\
\hline \multicolumn{3}{|l|}{ Percepciones mediáticas } \\
\hline $\begin{array}{l}\text { Hay muy pocas informaciones en los medios de comunicación que hablan } \\
\text { exactamente de lo que pienso de la política de mi país }\end{array}$ & 4.50 & .750 \\
\hline $\begin{array}{l}\text { Considero que la cobertura informativa que hacen los medios de mi país es } \\
\text { sesgada }\end{array}$ & 5.00 & .900 \\
\hline $\begin{array}{l}\text { La mayoría de los medios de comunicación informan más acerca de puntos de } \\
\text { vista distintos al mío que aquellos que dan cuenta de mis opiniones }\end{array}$ & 4.25 & .750 \\
\hline $\begin{array}{l}\text { En general, considero que la cobertura de los medios de mi país solo muestra } \\
\text { lo que le interesa a una sola de las partes }\end{array}$ & 4.75 & .900 \\
\hline \multicolumn{3}{|l|}{ Actitudes políticas } \\
\hline $\begin{array}{l}\text { Los legisladores y representantes políticos en general pierden muy } \\
\text { rápidamente el contacto con el pueblo }\end{array}$ & 3.75 & 675 \\
\hline $\begin{array}{l}\text { Las diferencias entre la gente común y la élite gobernante son mucho } \\
\text { mayores que las diferencias entre la misma gente común }\end{array}$ & 4.50 & .750 \\
\hline $\begin{array}{l}\text { La gente como yo no tiene ninguna influencia en lo que el gobierno hace o } \\
\text { deja de hacer }\end{array}$ & 4.50 & .750 \\
\hline Los políticos hablan mucho, pero hacen muy poco & 4.00 & .800 \\
\hline La gente común es tratada como una masa & 3.50 & .650 \\
\hline La gente común es buena y honesta & 3.50 & .650 \\
\hline La gente común comparte los mismos intereses y valores & 3.25 & .725 \\
\hline $\begin{array}{l}\text { Aunque la gente de mi país es muy diferente entre sí, cuando llega el } \\
\text { momento, todos piensan igual }\end{array}$ & 4.00 & .700 \\
\hline $\begin{array}{l}\text { La gente debe tener la decisión final en los asuntos políticos más importantes } \\
\text { votándolos en referendos }\end{array}$ & 4.75 & .850 \\
\hline Se debe preguntar a la gente cada vez que se toman decisiones importantes & 4.75 & .850 \\
\hline $\begin{array}{l}\text { La gente y no los políticos son los que deben tomar las decisiones más } \\
\text { importantes }\end{array}$ & 4.50 & .800 \\
\hline Los políticos deben seguir los deseos de la gente & 4.50 & .800 \\
\hline TOTAL & 4.46 & .770 \\
\hline
\end{tabular}

Nota: Todas las dimensiones eran preguntas con opción de respuesta en escala de Likert, excepto * que era una escala del 1-extrema izquierda y 10-extrema derecha. El valor de valoración interjueces también era una escala de Likert 1-5.

Fuente: Elaboración propia.

\subsection{Participantes}

El instrumento referido ut supra fue aplicado a un total de $n=511$ participantes, estudiantes de grados y postgrados afines a Ciencias de la Comunicación (periodismo, comunicación audiovisual, publicidad y relaciones públicas, comunicación corporativa) de Colombia y España. Tras eliminar los casos perdidos, la muestra efectiva $\left(\mathrm{M}_{\mathrm{E}}\right)$ quedó configurada por $\mathrm{n}=499$. 
Se elige trabajar con estudiantes de Ciencias de la Comunicación de Colombia y España por el contexto político contemporáneo de ambos países, que en las últimas campañas presidenciales experimentaron un discurso político polarizado que no caducó en las elecciones, sino que se fortalece cada día más. En esa construcción antagónica del relato que hacen los diferentes actores, se evidencian elementos característicos de actitudes populistas que fragmentan la discusión y obstaculizan el diálogo social necesario para el sano ejercicio democrático. En ambos casos, se elige una muestra con perfiles similares en cuanto a edad, género, educación, uso de plataformas digitales y temas afines.

Se observó que hubo un $56.3 \%$ de encuestados españoles, frente a un $43.7 \%$ de colombianos. La distribución por edad refleja una concentración muy elevada entre los jóvenes de entre 18 y 24 años, que componen el $90.6 \%$ de la muestra, con $n=452$; seguidos por el grupo etario 25-34 años, con un $6.2 \%$, y las de 35 a 44, con un $1.8 \%$ del total. Por su parte, en lo que respecta al género, se observa una mayoría de mujeres, que, con $n=336$ equivalen a un $67.3 \%$ de la muestra, mientras que los 163 hombres representan un $32.7 \%$.

En lo relativo al nivel educativo, 270 personas, un $54.1 \%$ de la muestra, afirmó poseer estudios hasta educación secundaria, 124 (un 24.8\%) hasta universidad, 83 (un 16.6\%), tienen formación técnica y 20 personas (un 4\%) están en posesión de estudios de máster.

\subsection{Procedimiento}

Se llevaron a cabo pruebas estadísticas descriptivas e inferenciales en el paquete SPSS de IBM (v. 26). Se realizaron pruebas, principalmente, $t$ de Student para muestras independientes, correlaciones bivariadas con el estadístico $\mathrm{R}$ de Pearson, tablas cruzadas con el estadístico Chi Cuadrado ( $\mathrm{x}^{2}$ ), y pruebas ANOVA de un factor. También se construyó un modelo de regresión lineal múltiple para determinar el rol de las variables independientes como variables predictoras de la percepción de la opinión pública.

\section{Resultados}

Primeramente, el estudio permitió establecer que las redes sociales son el medio más común para acceder a la información para 185 de los encuestados (37.1\%), seguido de los medios enteramente digitales, con 121 casos (24.2\%), la combinación de medios impresos y audiovisuales (con 115 casos y un $23 \%$ de la muestra), y la televisión (57 casos y un 11.4\%). El grado de interés en la política de los encuestados es moderadamente alto $(\mathrm{M}=3.40$, $\mathrm{DT}=1.058$, con una escala de 5$)$, mientras que la tendencia ideológica se sitúa ligeramente hacia la izquierda $(\mathrm{M}=4.32, \mathrm{DT}=2.124$, con una escala de 10) y el grado de extremismo político se situó en valores no extremadamente alejados del centro $(\mathrm{M}=3.27, \mathrm{DT}=1.465$, con una escala de 6$)$.

\subsection{Valores generales}

El índice de percepción de la opinión pública arrojó un valor medio de 2.75 (DT=0.684) y el índice de percepción mediática se situó en $3.54(\mathrm{DT}=0.741)$. El índice de actitudes anti-elitistas es el más elevado, con una media de 4.09 (DT=0.648), mientras que el índice de homogeneidad y virtud de la sociedad se encuentra en el 2.96 (DT=0.595). Por último, el índice de soberanía popular se encuentra en el 3.75 (DT=0.789).

De manera más detallada, conviene destacar algunos ítems, como la afirmación "Los políticos hablan mucho, pero hacen muy poco", que, con una media de $4.35(\mathrm{DT}=0.819)$ es la más elevada, mientras 
que la afirmación "La mayoría de las personas de mi país opinan de la política de la misma forma que yo" solo obtiene una media de 2.46 (DT=0.836), siendo la más baja de todas. Por último, se creó un índice de actitudes populistas, compuesto por el índice de actitudes anti-elitistas, el índice de homogeneidad y virtud de la ciudadanía y el índice de soberanía popular. Este índice arrojó una media de 3.60 ( $\mathrm{DT}=0.476)$. Todos los valores pueden observarse en la Tabla 2.

Tabla 2. Valores medios de los ítems para el conjunto de la muestra

\begin{tabular}{|c|c|c|c|}
\hline & $\mathrm{N}$ & M & DT \\
\hline $\begin{array}{l}\text { Mi opinión acerca de la política en mi país es similar a muchas de las opiniones de } \\
\text { aquellos que me rodean y que sigo en las redes sociales }\end{array}$ & & 3,19 & 0.974 \\
\hline $\begin{array}{l}\text { En la ciudad donde vivo, la mayoría de las personas piensan sobre la política de mi } \\
\text { país de la misma forma que yo }\end{array}$ & 499 & 2,60 & 0.963 \\
\hline La mayoría de las personas de mi país opinan de la política de la misma forma que yo & 499 & 2,46 & 0.836 \\
\hline Índice de percepción de la opinión pública & 499 & 2,75 & 0.684 \\
\hline $\begin{array}{l}\text { Hay muy pocas informaciones en los medios de comunicación que hablan } \\
\text { exactamente de lo que pienso de la política de mi país }\end{array}$ & 499 & 3,17 & 1.105 \\
\hline Considero que la cobertura informativa que hacen los medios de mi país es sesgada & 499 & 3,93 & 0.978 \\
\hline $\begin{array}{l}\text { La mayoría de los medios de comunicación informan más acerca de puntos de vista } \\
\text { distintos al mío que aquellos que dan cuenta de mis opiniones }\end{array}$ & 499 & 3,25 & 0.892 \\
\hline $\begin{array}{l}\text { En general, considero que la cobertura de los medios de mi país solo muestra lo que le } \\
\text { interesa a una sola de las partes }\end{array}$ & 499 & 3,82 & 1.042 \\
\hline Índice de percepción mediática & 499 & 3,54 & 0.741 \\
\hline $\begin{array}{l}\text { Los legisladores y representantes políticos en general pierden muy rápidamente el } \\
\text { contacto con el pueblo }\end{array}$ & 499 & 4,15 & 0.892 \\
\hline $\begin{array}{l}\text { Las diferencias entre la gente común y la élite gobernante son mucho mayores que las } \\
\text { diferencias entre la misma gente común }\end{array}$ & 499 & 4,23 & 0.891 \\
\hline $\begin{array}{l}\text { La gente como yo no tiene ninguna influencia en lo que el gobierno hace o deja de } \\
\text { hacer }\end{array}$ & 499 & 3,64 & 1.171 \\
\hline Los políticos hablan mucho, & 499 & 4,35 & 0.819 \\
\hline Índic & 499 & 4,09 & 0.648 \\
\hline La ge & 499 & 4,35 & 0.820 \\
\hline La gente común es buena y honesta & 499 & 2,90 & 0.930 \\
\hline La gente común comparte los mismos intereses y valores & 499 & 2,30 & 0.997 \\
\hline $\begin{array}{l}\text { Aunque la gente de mi país es muy diferente entre sí, cuando llega el momento, todos } \\
\text { piensan igual }\end{array}$ & 499 & 2,30 & 1.026 \\
\hline Índice de homogeneidad y virtud de la ciudadanía & 499 & 2,96 & 0.595 \\
\hline $\begin{array}{l}\text { La gente debe tener la decisión final en los asuntos políticos más importantes } \\
\text { votándolos en referendos }\end{array}$ & 499 & 3,85 & 1.035 \\
\hline Se debe preguntar a la gente cada vez que se toman decisiones importantes & 499 & 3,96 & 1.043 \\
\hline La gente y no los políticos son los que deben tomar las decisiones más importantes & 499 & 3,36 & 1.097 \\
\hline Los políticos deben seguir los deseos de la gente & 499 & 3,83 & 0.984 \\
\hline Índice de soberanía popular & 499 & 3,75 & 0.789 \\
\hline Índice de actitudes populistas & 499 & 3.60 & 0.476 \\
\hline
\end{tabular}

Fuente: Elaboración propia.

\subsection{Diferencias por país}

Centrados ya en las diferencias entre los dos países en estudio, España y Colombia, se observan diferencias significativas en 4 de los 5 índices. Así, se aprecia que el índice de percepción de la opinión pública es significativamente mayor en España $(M=2.83$, DT $=0.639)$ que en Colombia $(\mathrm{M}=2.65, \mathrm{DT}=0.726),[\mathrm{t}(497)=2.903, \mathrm{p}<0.01, \mathrm{~d}=0.31]$. En el resto de casos se observa el caso contrario. 
Así, el índice de percepción mediática es significativamente superior en Colombia ( $\mathrm{M}=3.82$, $\mathrm{DT}=0.692)$ que en España $(\mathrm{M}=3.32, \mathrm{DT}=0.706),[\mathrm{t}(497)=-7.824, \mathrm{p}<0.001, \mathrm{~d}=0.72]$. Lo mismo sucede con el índice de actitudes anti-elitistas, que es significativamente superior en Colombia $(\mathrm{M}=4.23$, DT=0.667) que en España $(\mathrm{M}=3.99, \mathrm{DT}=0.613),[\mathrm{t}(497)=-4.259, \mathrm{p}<0.001, \mathrm{~d}=0.37]$. También el índice de homogeneidad y virtud de la ciudadanía es significativamente mayor en Colombia ( $\mathrm{M}=3.12$, DT=0.640) que en España $(\mathrm{M}=2.84, \mathrm{DT}=0.527)$, [t(497)=-5.383, $\mathrm{p}<0.001$, $\mathrm{d}=0.48$ ], y lo mismo sucede con el índice de actitudes populistas, que es significativamente mayor en Colombia $(\mathrm{M}=3.70, \mathrm{DT}=0.517)$ que en España $(\mathrm{M}=3.52$, DT=0.426), $[\mathrm{t}(416.585)=-4.062, \mathrm{p}<0.001$, $\mathrm{d}=0.38]$. El índice de soberanía popular no arrojó diferencias significativas entre ambos países.

Cabe señalar que existen otras diferencias entre países. Así, la población española es significativamente más joven: el grupo de edad entre 18 y 24 años está más representado en España que en Colombia (5.1>1.96), mientras que los grupos de edad de entre 25 y 34 (3.2>1.96), entre 35 y $44(3.4>1.96)$ y entre 45 y $54(2.3>1.96)$ están más representados en Colombia que en España $\left[\mathrm{X}^{2}(5)=31.927, \mathrm{p}<0.001\right]$. Al mismo tiempo, los medios utilizados para informarse son diferentes entre ambos países: mientras que en Colombia están proporcionalmente más presentes los medios impresos y audiovisuales (4.9>1.96) y la opción de «todos las anteriores» (2.3>1.96), en España es proporcionalmente más frecuente el uso de las redes sociales $(4.6>1.96)$ y de la televisión $(2.8>1.96)$ $\left[\mathrm{X}^{2}(5)=49.054, \mathrm{p}<0.001\right]$.

Por su parte, el interés en la política es superior en Colombia $(\mathrm{M}=3.59, \mathrm{DT}=1.008)$ que en España $(\mathrm{M}=3.25, \mathrm{DT}=1.073),[\mathrm{t}(497)=-3.631, \mathrm{p}<0.001, \mathrm{~d}=0.33]$, al tiempo que la población colombiana $(\mathrm{M}=4.70, \mathrm{DT}=1.788)$ parece tener una ideología significativamente más a la derecha que la española $(\mathrm{M}=4.03, \mathrm{DT}=2.314),[\mathrm{t}(496.995)=-3.623, \mathrm{p}<0.001, \mathrm{~d}=0.32]$. También se observa que el nivel de extremismo político es significativamente mayor en España $(\mathrm{M}=3.65$, DT=1.478) que en Colombia $(\mathrm{M}=2.79, \mathrm{DT}=1.299),[\mathrm{t}(489.276)=6.922, \mathrm{p}<0.001, \mathrm{~d}=0.62]$.

Donde no se observan diferencias significativas es en la distribución por género, ni tampoco en el nivel de estudios, salvo por la proporción de personas con estudios de maestría, significativamente superior en Colombia que en España $(4.3>1.96)$ [ $\left.\mathrm{X}^{2}(5)=21.963, \mathrm{p}<0.01\right]$.

En resumen, se puede observar que los índices tienen valores generalmente más altos en Colombia, salvo en el caso del índice de percepción de la opinión pública, que observamos antes que sigue un patrón ligeramente diferente al resto, y que es superior en España. Las diferencias son, además, de mayor tamaño en los cuatro casos en los que Colombia supera a España. A pesar de la existencia de diferencias en otros aspectos, como la edad, el tipo de medios del que se obtiene la información, el interés en la política o en la ideología, el efecto de estas cuestiones no resulta determinante y no existe una tendencia clara.

\subsection{Diferencias sociodemográficas}

Dado que existen varios grupos etarios con un número muy reducido de casos, no se pudo realizar la prueba ANOVA de un factor, por lo que se optó por establecer correlaciones, de manera exploratoria, para buscar potenciales diferencias derivadas de la edad. Lo mismo sucedió con el nivel educativo. En este sentido, los resultados permiten afirmar que no se observaron correlaciones significativas entre estas variables y los cinco índices analizados, salvo entre el índice de homogeneidad y virtud de la ciudadanía y el nivel educativo, que se relacionan de manera positiva pero débil $[\mathrm{R}(499)=0.106, \mathrm{p}<0.05]$. Sí se observaron correlaciones significativas y positivas entre el interés por la política y la edad del encuestado $[R(499)=0.147, \mathrm{p}<0.01]$, y también entre el interés por la política y el nivel educativo $[\mathrm{R}(499)=0.110, \mathrm{p}<0.05]$. 
Dado que el grupo etario con mayor presencia es el de los más jóvenes, se analizó la potencial presencia de diferencias entre los menores de 24 años y quienes tienen más de esa edad. Tampoco se observaron diferencias significativas en ninguno de los índices, y solo se percibieron diferencias significativas en lo referente al interés en la política, significativamente mayor en las personas de más de 24 años $(\mathrm{M}=3.87, \mathrm{DT}=1.191)$ que entre las menores de esa edad $(\mathrm{M}=3.35, \mathrm{DT}=1.032)$, $[\mathrm{t}(497)=-3.254, \mathrm{p}<0.01, \mathrm{~d}=0.47]$.

También se llevó a cabo una prueba t de Student para comparar a quienes tienen estudios universitarios con quienes no los tienen. Apenas se observaron diferencias significativas, salvo en el índice de homogeneidad y virtud, superior entre quienes tienen estudios universitarios $(\mathrm{M}=3.06$, $\mathrm{DT}=0.634)$ que entre quienes no los tienen $(\mathrm{M}=2.92$, DT $=0.575),[\mathrm{t}(246.058)=-2.320, \mathrm{p}<0.05$, $\mathrm{d}=0.23$ ]. Lo mismo sucedió con respecto al interés en la política, mayor entre quienes tienen estudios universitarios $(\mathrm{M}=3.32$, $\mathrm{DT}=1.021)$ que entre quienes no los tienen $(\mathrm{M}=3.58, \mathrm{DT}=1.128)$, $[\mathrm{t}(497)=-$ $2.451, \mathrm{p}<0.05, \mathrm{~d}=0.24]$.

En lo que respecta al tipo de medios utilizados para consumir información, la prueba ANOVA también estuvo limitada por el reducido número de casos en algunas categorías, si bien se pudo apreciar que solo existen diferencias significativas en lo relativo al interés por la política $[\mathrm{F}(8$, $490)=5.002, \mathrm{p}<0.001]$. De manera exploratoria, y dado que la polarización, el populismo y la desinformación son fenómenos frecuentemente asociados al ascenso de las redes sociales como fuentes de información, se realizaron pruebas $\mathrm{t}$ de Student para determinar si existen diferencias significativas entre quienes consumen preferentemente información de redes sociales y mensajería y quienes lo hacen a través del resto de medios. Estas pruebas tampoco arrojaron diferencias significativas en ninguna de las variables estudiadas.

En lo que respecta al género, solo en el índice de percepción de la opinión pública se observó que las mujeres $(\mathrm{M}=2.80, \mathrm{DT}=0.647)$ mostraron valores significativamente superiores a los hombres $(\mathrm{M}=2.65, \mathrm{DT}=0.746),[\mathrm{t}(497)=-2.313, \mathrm{p}<0.05, \mathrm{~d}=0.21]$. También se observa que los hombres $(\mathrm{M}=3.58, \mathrm{DT}=1.122)$ tienen significativamente más interés en la política que las mujeres $(\mathrm{M}=3.31$, $\mathrm{DT}=1.017),[\mathrm{t}(294.248)=2.543, \mathrm{p}<0.05, \mathrm{~d}=0.25]$. Ni en el resto de índices, ni en la ideología política y el extremismo político, se observaron diferencias significativas derivadas del género.

\subsection{Diferencias políticas}

En primer lugar, conviene apuntar la existencia de una correlación débil, pero significativa entre el interés en la política y la ideología $[\mathrm{R}(499)=-0.092$, p<0.05], estando las personas de izquierda ligeramente más interesadas en política. Por su parte, existe una correlación positiva y significativa entre el interés en política y el grado de extremismo político $[\mathrm{R}(499)=0.146, \mathrm{p}<0.01]$. Al mismo tiempo, la correlación entre la ideología y el grado de extremismo es positiva y de tamaño notable, con ideologías más alejadas del centro entre las personas de izquierda $[R(499)=-0.659, \mathrm{p}<0.001]$.

El interés en la política también se correlaciona de manera positiva y moderada con el índice de percepción mediática $[\mathrm{R}(499)=0.165, \mathrm{p}<0.001]$. Por su parte, la tendencia ideológica se correlaciona de manera significativa con el índice de homogeneidad y virtud $[R(499)=0.118, p<0.01]$, mayor entre las personas de derecha, y el índice de soberanía popular [R(499)=-0.171, $\mathrm{p}<0.001]$, mayor entre las personas de izquierda. Finalmente, el grado de extremismo político muestra una correlación significativa y negativa con el índice de homogeneidad y virtud $[R(499)=-0.104, p<0.05]$, y una correlación significativa y positiva con el índice de soberanía popular $[R(499)=-0.160$, $p<0.001]$. 


\subsection{Correlaciones entre índices}

El índice de percepción de la opinión pública se correlaciona de manera significativa y negativa con el índice de percepción mediática $[\mathrm{R}(499)=-0.143$, $\mathrm{p}<0.01]$, y de manera positiva con el índice de homogeneidad y de virtud $[R(499)=0.166, \mathrm{p}<0.001]$.

El índice de percepción mediática se correlaciona significativa y positivamente con el índice de actitudes anti-elitistas $[\mathrm{R}(499)=0.370, \mathrm{p}<0.001]$, el índice de homogeneidad y virtud de la ciudadanía $[R(499)=0.193, p<0.001]$ y el índice de soberanía popular $[R(499)=0.242, p<0.001]$. El índice de actitudes anti-elitistas se correlaciona, además, con el índice de homogeneidad y virtud de la ciudadanía $[\mathrm{R}(499)=0.219, \mathrm{p}<0.001]$ y con el índice de soberanía popular $[\mathrm{R}(499)=0.285, \mathrm{p}<0.001]$, en ambos casos de manera positiva. Finalmente, el índice de homogeneidad y virtud de la ciudadanía y el de soberanía popular se correlacionan de manera significativa y positiva $[R(499)=0.190$, $\mathrm{p}<0.001]$.

Se observa, por lo tanto, que solo el índice de percepción de la opinión pública sigue un patrón ligeramente diferente, mientras que los otros cuatro índices siguen un patrón semejante, si bien las correlaciones son en general de tamaño moderado o medio.

\subsection{Modelo de regresión}

Por último, se realizó un modelo de regresión lineal múltiple (ver Tabla 3), considerando el país, la edad, el nivel educativo, el género, el interés político, el posicionamiento político, el grado de extremismo político, las actitudes populistas y la percepción mediática como variables predictoras y considerando la percepción de la opinión pública como variable dependiente. Este modelo se diseñó a partir de la investigación de Schulz, Wirth y Müller (2018). 
RLCS, Revista Latina de Comunicación Social, 79, 43-66

[Investigación] DOI: 10.4185/RLCS-2021-1507| ISSN 1138-5820 | Año 2021

Tabla 3. Correlaciones entre las variables que se tuvieron en cuenta para realizar el análisis de Regresión lineal múltiple

\begin{tabular}{|c|c|c|c|c|c|c|c|c|c|c|c|}
\hline & & POP & $\begin{array}{l}\text { EXT } \\
\text { POL }\end{array}$ & $\begin{array}{l}\text { ACT } \\
\text { POP }\end{array}$ & País & $\begin{array}{c}\text { Géner } \\
\text { o }\end{array}$ & $\begin{array}{l}\text { PERC } \\
\text { MED }\end{array}$ & $\begin{array}{l}\text { INT } \\
\text { POL }\end{array}$ & $\begin{array}{l}\text { ID } \\
\text { POL }\end{array}$ & Edad & $\begin{array}{c}\text { EDU } \\
\mathrm{C}\end{array}$ \\
\hline \multirow{10}{*}{$\dot{0}$} & $\begin{array}{c}\text { Percepción de la Opinión } \\
\text { Pública } \\
\end{array}$ & 1.000 & 0.078 & 0.065 & -0.129 & 0.103 & -0.143 & -0.021 & 0.011 & -0.016 & -0.067 \\
\hline & Extremismo político & 0.078 & 1.000 & 0.052 & -0.292 & 0.043 & -0.014 & 0.146 & -0.659 & 0.017 & -0.022 \\
\hline & Actitudes Pop & 965 & 0.052 & 1.000 & 83 & -0.049 & 0.383 & -0.014 & -0.052 & 0.005 & 0.041 \\
\hline & País & -0.129 & -0.292 & 0.183 & 1.000 & -0.058 & 0.331 & 0.161 & 0.155 & 0.205 & 0.066 \\
\hline & Género & 0.103 & 0.043 & -0.049 & -0.058 & 1.000 & -0.034 & -0.117 & -0.007 & -0.186 & -0.032 \\
\hline & Percepción Mediática & -0.143 & -0.014 & 0.383 & 0.331 & -0.034 & 1.000 & 0.165 & 0.003 & 0.052 & 0.079 \\
\hline & Interés en política & -0.021 & 0.146 & -0.014 & 161 & -0.117 & 0.165 & 1.000 & -0.092 & 0.147 & 0.110 \\
\hline & Ideología pol & 011 & -0.659 & -0.052 & & -0.007 & 0.003 & -0.092 & 1.000 & -0.060 & 0.041 \\
\hline & & & 0.017 & -0.005 & & & 0.052 & 0.147 & -0.060 & & 0.401 \\
\hline & vel educ & & -0.022 & 0.041 & & -0.032 & 0.079 & 0.110 & 0.041 & & 1.000 \\
\hline \multirow{10}{*}{ 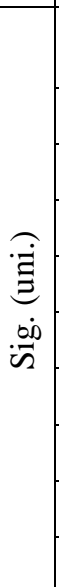 } & $\begin{array}{l}\text { Percepción de la Opinión } \\
\text { Pública }\end{array}$ & & 0.040 & 0.075 & 0.002 & 0.011 & 0.001 & 0.320 & 0.407 & 0.362 & 0.067 \\
\hline & Extremismo político & 0.040 & & 0.124 & 000 & 0.169 & 0.374 & 0.001 & 0.000 & 355 & 0.316 \\
\hline & Actitudes Populistas & 075 & 0.124 & & 0.000 & 0.139 & 0.000 & 0.378 & 0.122 & 453 & 0.181 \\
\hline & País & 0.002 & 0.000 & 0.000 & & 0.096 & 0.000 & 0.000 & 0.000 & 0.000 & 0.069 \\
\hline & Género & 0.011 & 0.169 & 0.139 & 0.096 & . & 0.224 & 0.004 & 0.439 & 0.000 & 0.236 \\
\hline & Percepción Mediática & 0.001 & 0.374 & 0.000 & 0.000 & 0.224 & & 0.000 & 0.475 & 0.123 & 0.040 \\
\hline & Interés en política & 0.320 & 0.001 & 0.378 & 0.000 & 0.004 & 0.000 & & 0.020 & 0.000 & 0.007 \\
\hline & Ideología política & 0.407 & 0.000 & 0.122 & 0.000 & 0.439 & 0.475 & 0.020 & & 0.089 & 0.181 \\
\hline & Edad & 0.362 & 0.355 & 0.453 & 0.000 & 0.000 & 0.123 & 0.000 & 0.089 & . & 0.000 \\
\hline & Nivel educativo & 0.067 & 0.316 & 0.181 & 0.069 & 0.236 & 0.040 & 0.007 & 0.181 & 0.000 & \\
\hline
\end{tabular}

Fuente: Elaboración propia.

El modelo de regresión lineal múltiple (Tabla 4) basado en las variables predictoras explicó el 5,4\% de la varianza de la percepción de la opinión pública $\left[\mathrm{R}=0.071, \mathrm{R}^{2}\right.$ ajustada $=0.054, \mathrm{~F}(9,498)=4.14$, $\mathrm{p}=0.001)$. El análisis de los coeficientes de regresión estandarizados muestra que la intención política (beta $=0.03, p=0.48$ ), la edad (beta $=0.06, p=0.17$ ) y el hecho de ser políticamente extremo (beta $=0.10$, $\mathrm{p}=0.10$ ) no se asociaba significativamente con las percepciones de opinión pública. Sin embargo, las actitudes populistas (beta $=0.15, \mathrm{p}<0.001$ ) y el género (beta $=0.11, \mathrm{p}<0.05$ ) se asociaban de manera significativa con las percepciones de opinión pública. Así, las personas con actitudes populistas arrojaban más elevados en el índice de percepción de la opinión pública. Lo mismo sucedía con las personas de género femenino. Además, se observó que las percepciones mediáticas se asociaban de manera negativa con las percepciones de opinión pública (beta $=-0.16, \mathrm{p}<0.001$ ). Con ello, un índice más elevado de la percepción mediática se asocia con un índice más bajo de percepción de la opinión pública. 
RLCS, Revista Latina de Comunicación Social, 79, 43-66

[Investigación] DOI: 10.4185/RLCS-2021-1507| ISSN 1138-5820| Año 2021

Tabla 4. Modelo de regresión lineal múltiple

\begin{tabular}{|c|c|c|c|c|c|}
\hline & \multicolumn{2}{|c|}{ Coeficientes no estandarizados } & $\begin{array}{c}\text { Coeficientes } \\
\text { estandarizados }\end{array}$ & $\mathrm{t}$ & Sig. \\
\hline & $\mathrm{B}$ & Error típico & Beta & & \\
\hline (Constante) & 2.126 & 0.312 & & 6.821 & 0.000 \\
\hline Extremismo político & 0.047 & 0.029 & 0.101 & 1.646 & 0.100 \\
\hline Actitudes Populistas & 0.226 & 0.069 & 0.157 & 3.275 & 0.001 \\
\hline País & -0.134 & 0.070 & -0.097 & -1.925 & 0.055 \\
\hline Género & 0.160 & 0.065 & 0.110 & 2.447 & 0.015 \\
\hline Percepción Mediática & -0.155 & 0.046 & -0.168 & -3.365 & 0.001 \\
\hline Interés en política & 0.021 & 0.030 & 0.032 & 0.698 & 0.486 \\
\hline Ideología política & 0.036 & 0.019 & 0.112 & 1.922 & 0.055 \\
\hline Edad & 0.085 & 0.062 & 0.068 & 1.360 & 0.174 \\
\hline Nivel educativo & -0.059 & 0.034 & -0.084 & -1.739 & 0.083 \\
\hline
\end{tabular}

Fuente: Elaboración propia.

Por otro lado, se evidenció que el país (España o Colombia), la orientación política y nivel educativo, se asociaban de manera tendencial con las percepciones de opinión pública. Así las personas de España tenían valores más elevados en esta percepción que las de Colombia (beta=-0.097, p=0.055). De igual modo, aquellas personas más de derechas tienen valores más altos en el índice de percepción de la opinión pública (beta $=0.11, \mathrm{p}=0.055$ ). Y lo mismo sucede con aquellas personas con menos nivel educativo (beta $=-0.08, \mathrm{p}=0.08$ ).

\section{Discusión}

El estudio constata las preferencias de los jóvenes por las plataformas sociales, en su formación e interacción con la agenda política, tal y como han señalado diversos estudios como los de Piscitelli (2010), Schwarz (2011), Colás et al. (2013), Bernal y Angulo (2013) o Tejedor et al. (2018), entre otros. Sin embargo, el estudio identifica diferencias derivadas del contexto socio-cultural y socioeconómico que, en el caso colombiano, por ejemplo, potencia el uso de los medios impresos y audiovisuales, frente a los usuarios españoles que optan preferentemente por el uso de las redes sociales y de la televisión. Este dato invita, por tanto, a un monitoreo de las tendencias en las preferencias de uso de los jóvenes junto al impacto del factor contextual, teniendo en consideración el predominio de las plataformas digitales, como apunta Catalina-García et al. (2019).

El valor alcanzado por el índice de actitudes populistas, compuesto por el índice de actitudes antielitistas, el índice de homogeneidad y virtud de la ciudadanía y el índice de soberanía popular, alcanzó una media de 3.60 (DT=0.476), aspecto que invita a reflexionar sobre si existe un consenso terminológico alrededor del alcance de este concepto más allá de las líneas generales apuntadas por Gutiérrez (2011) y Espí (2019).

Este aspecto engarza con la ausencia de divergencias notables en la distribución por género o nivel de estudios. En Colombia, los índices tienen valores generalmente más altos, como sucede con los índices de actitudes antielitista y de percepción mediática, que puede estar relacionado con los problemas de inequidad social que se manifiestan en la población del país y que los jóvenes no ven reflejados en la agenda de los medios ni en el discurso de las élites. Tal y como lo expone Waisbord (2020), la partición mediática que se da en las plataformas digitales, permite contenidos ajustados a 
los intereses políticos particulares, pero termina reforzando simpatías, diferencias y odios que impiden el diálogo social. El único índice en el que España obtuvo un mayor valor fue el de percepción de la opinión pública.

La existencia de una correlación débil, pero significativa entre el interés en la política y la ideología con la que se identifican entronca con los postulados de Sadiki (2018), Lazer et al. (2018), Nyilasy (2019) y Waisbord (2020), debido a que aluden a la mediatización y fragmentación de la comunicación política, lo que deviene en la creación discursiva de la polarización social. La constatación de que las personas de izquierda están más interesadas en política refuerza la tendencia identificada por el Injuve (2017), que apuntó una diferencia entre aquellos jóvenes que se autoubican ideológicamente en la izquierda moderada en España.

Frente a la tendencia de ciertos actores, como apunta Waisbord (2020), que persiguen atraer simpatizantes mediante la deslegitimación de otros grupos de poder e instituciones, el estudio detecta la importancia de una apuesta creciente por la media literacy (Pérez Tornero et al., 2015). Este aspecto conecta con uno de los resultados del estudio que identifica como el interés en la política también se encuentra correlacionado de manera positiva y moderada con el índice de percepción mediática. Se plantea, por tanto, la necesidad de «educar la mirada crítica» de la ciudadanía frente a la actividad y los sujetos de la vida política.

Aunque las principales diferencias se derivan del país del encuestado, esta no es realmente la variable más determinante de cara a predecir la percepción de la opinión pública. El resto de variables no han arrojado más que algunas diferencias puntuales y no se puede afirmar que exista una tendencia clara en ninguna dirección, ni por interés, extremismo o ideología, ni tampoco en lo referente a variables sociodemográficas. En lo referente a la edad, los medios utilizados para informarse y el nivel educativo, la muestra impide recurrir a ANOVA, que sería lo más útil, pero se han utilizado distintas alternativas y en ningún caso se han observado grandes diferencias.

Sí existen correlaciones entre los distintos índices, demostrando su estrecha interconexión, y demostrando que, quien posee actitudes populistas es frecuente que las tenga en distintas dimensiones, y que su percepción de los medios y la opinión pública se relacione con estas actitudes. Esto es visible no solo en las correlaciones, sino también en el modelo de regresión, en el que las actitudes populistas y la percepción mediática son las variables más influyentes. Sin embargo, resulta llamativo que la percepción mediática lo haga en la dirección opuesta, como también sucedió con la correlación entre ambos índices. Este resultado puede explicarse porque los ítems del índice de percepción de la opinión pública se construyen con afirmaciones positivas sobre el grado de acuerdo con otras personas, mientras que el índice de percepción mediática se construye con afirmaciones en negativo sobre el grado de desacuerdo con los medios.

No se evidencia una clara articulación entre las actitudes populistas y una ideología política de extremos y esto corrobora lo que Mudde y Rovira (2019) explican sobre el populismo, que no se caracteriza por una ideología fundante, sino que se nutre de otras líneas de pensamiento, de la crítica, la polarización y el conflicto.

\section{Conclusiones}

El trabajo aborda una temática de creciente relevancia que demanda de un trabajo continuado desde la academia en aras de analizar las motivaciones, las dinámicas y las percepciones que los jóvenes, en el conjunto del contexto iberoamericano, desarrollan en el escenario político. En el marco de una sociedad globalizada, el estudio comparativo entre grupos de edad semejantes ubicados en contextos 
socio-culturales y socio-económicos distintos puede aportar reflexiones de gran valor en la conceptualización, la categorización y, en definitiva, el estudio de las percepciones políticas, mediáticas, de opinión pública y, de forma general, las actitudes políticas de la juventud actual y de las futuras generaciones.

Los resultados del estudio permitieron lograr el objetivo propuesto de examinar las correlaciones entre las actitudes populistas, la percepción de la opinión pública y las opiniones sobre los medios de comunicación en estudiantes de Ciencias de la Comunicación de Colombia y España. De acuerdo al análisis realizado se respondieron las hipótesis planteadas: si las actitudes populistas de una persona se hacen más fuertes, no necesariamente percibirá mayor congruencia de la opinión pública sobre sus propias opiniones, el índice arrojó lo contrario en ambos países, siendo mayor el índice en los resultados de España. Asimismo, se evidencia que cuando las actitudes populistas de una persona se fortalecen, percibe las informaciones de los medios de comunicación como incongruentes con sus puntos de vista. Y, por último, el incremento de las actitudes populistas de una persona también aumenta la diferencia entre la congruencia de la opinión pública y la hostilidad de los medios de comunicación.

Al relacionar la información obtenida con los datos del contexto español y colombiano sobre la participación e información política de los jóvenes, se constata una tendencia al desapego y descrédito de la población joven frente a la faceta política. El peso de la afirmación destacada en este estudio que cuestionaba la falta de acciones por parte de los políticos frente a su excesivo uso de la retórica ("Los políticos hablan mucho, pero hacen muy poco") alude a los actores políticos, pero afecta igualmente a las instituciones. Las diferencias entre España y Colombia, en algunos resultados, denota el peso que ciertos aspectos poseen en la topicalización de los procesos y en la proyección de la vida política entre la ciudadanía. Por ejemplo, el hecho de que el índice de percepción de la opinión pública sea significativamente mayor en España que en Colombia, mientras que el de percepción mediática o el de actitudes anti-elitistas son ligeramente mayores en Colombia.

Por un lado, la investigación incide en el rol protagónico que el ecosistema mediático posee en la interacción entre la ciudadanía, especialmente, los perfiles más jóvenes, y la vida política. En este sentido, el estudio enfatiza la necesidad de desarrollar nuevos trabajos alrededor del papel de los medios digitales versus los medios impresos y audiovisuales, cuya importancia sigue siendo perceptible, sobre todo en América Latina. La caída de la televisión, sin embargo, invitaría al desarrollo de estudio alrededor de la idoneidad de redefinir formatos y propuestas de cariz más innovador ante un público que se informa e interacciona sobre la política a través de las pantallas conectadas al ciberespacio.

Desde el modelo de las tres dimensiones de las actitudes populistas de Schultz, Wirth y Müller (2020) se logra cuantificar cada uno de los asuntos de las actitudes populistas y su correlación, pero sería pertinente en próximos estudios profundizar sobre la participación política, la confianza en las instituciones del sistema democrático y los referentes, influencers y prescriptores a los que acuden los estudiantes de Comunicación para informarse y fijarse una opinión de los asuntos políticos de ambos países. Esto permitiría cruzar las dimensiones de las percepciones y de la participación ciudadana. Asimismo, corroborar dicho modelo con estudiantes de otras profesiones de los mismos países para evaluar cambios en las percepciones mediáticas y de opinión de acuerdo a la formación profesional.

El estudio desarrollado permite concluir que las redes sociales conforman un elemento decisivo en este tipo de investigaciones y, en esta línea, ahondan en la importancia de promover trabajos de cariz interdisciplinar que permitan identificar y analizar los vínculos entre los aspectos comunicativos y la 
visión de la ciudadanía en el escenario político. Con relación a este aspecto, la media literacy constituye un elemento de crucial importancia.

\section{Referencias}

Alhabash, S., Hyojung, K., Anastasia, C., Y., y Wise, K. (2012). Exploring the Motivations of Facebook Use in Taiwan. Cyberpsychology, Behavior, and Social Networking, 15(6), 304-311. https://doi.org/10.1089/cyber.2011.0611

Badjatiya, P., Gupta, S., Gupta, M., y Varma, V. (2017). Deep learning for hate speech detection in tweets. En: Proceedings of the 26th International Conference on World Wide Web Companion (pp. 759-760). https://doi.org/10.1145/3041021.3054223

Baek, K., Holton, A., Harp, D., y Yaschur, C. (2011). The link that bind: Uncovering novel motivations for linking on Facebook. Computers in Human Behavior, 27(6), 2243-2248. https://doi.org/10.1016/j.chb.2011.07.003

Bernal, C., y Angulo, F. (2013). Interacciones de los jóvenes andaluces en las redes sociales. Comunicar, 20(40), 25-30. https://doi.org/10.3916/C40-2013-02-02

Blanco, A., y De la Corte, L. (2003). Psicología social de la violencia. En I. Martín-Baró (Coord.). Poder, violencia e ideologia. (pp. 9-62). Trotta.

Catalina-García, B., Sousa, J.P., y Li-Chang S. (2019). Consumo de noticias y percepción de fake news entre estudiantes de Comunicación de Brasil, España y Portugal. Revista de Comunicación, 18(2), 93-115. https://dx.doi.org/10.26441/rc18.2-2019-a5

Canel, M. (1999). Comunicación Política. Técnicas y estrategias para la sociedad de la información. Tecnos.

Carey, J. (1999). La democracia mediática: Democracia mediática y campañas electorales. En A. Muñoz Alonso (Coord.). The Mass Media and Democracy, Between the Modern and the Postmodern. Ariel.

Castilla, S. (2020). Derecha radical y populismo: Un análisis comparado entre Agrupación Nacional y Vox en Twitter. Universidad de Salamanca. http://dx.doi.org/10.13140/RG.2.2.21850.98247

Cervi, L., \& Tejedor, S. (2021). "Toda África no cabe en Europa" : Análisis comparativo de los discursos de los partidos anti inmigración en España y en Italia. Migraciones. Publicación Del Instituto Universitario De Estudios Sobre Migraciones, (51), 207-239. https://doi.org/10.14422/mig.i51y2021.008

Cervi, L.; Tejedor, S. (2020). Framing "The Gypsy Problem": Populist Electoral Use of Romaphobia in Italy (2014-2019). Soc. Sci. 9, 105. https://doi.org/10.3390/socsci9060105

Civila, S., Romero-Rodríguez, L.M., y Civila, A. (2020). The Demonization of Islam through Social Media: A Case Study of \#Stopislam in Instagram, Publications, 8(4), 52. https://doi.org/10.3390/publications8040052 
Cheung, C., Chiu, P., y Lee, M. (2011). Online social networks: Why do students use Facebook? Computers in Human Behavior, 27(4), 1337-1343. https://doi.org/10.1016/j.chb.2010.07.028

Chung, T., Anaza, N., Park, J., y Phillips, A. (2016). Who's behind the screen? Segmenting social venture consumers through social media usage. Journal of Retailing and Consumer Services, 28, 288-295. https://doi.org/10.1016/j.jretconser.2015.01.006

Colás, P., González, T., y de Pablos, J. (2013). Juventud y redes sociales: Motivaciones y usos preferentes. Comunicar, 20(40),15-23. https://doi.org/10.3916/C40-2013-02-01

Dader, J.L. (1990). La personalización de la política. En A. Muñoz Alonso (Coord.). Opinión Pública y Comunicación Política. Eudema.

Del Pino, M.S., y Goenechea Permisán, C. (2020). Literacidad crítica y medios de comunicación: el profesorado en formación ante el discurso del odio. Investigaciones sobre Lectura, (14), 181-212. https://doi.org/10.24310/isl.vi14.12239

Dirección Nacional de Estadística. (2020). Panorama sociodemográfico de la juventud en Colombia. Disponible en: https://www.dane.gov.co/files/investigaciones/genero/informes/informepanorama-sociodemografico-juventud-en-colombia.pdf

Espí, A. (2019). La dimensión emocional de los movimientos políticos populistas del s. XXI en América Latina y Europa. Miguel Hernández Communication Journal, 10(1), 101-121. https://doi.org/10.21134/mhcj.v10i0.277

Gómez de Travesedo-Rojas, R., y Gil Ramírez, M. (2020). Generación Z y consumo de información política: entre la televisión y los nuevos formatos mediáticos. Ámbitos. Revista Internacional de Comunicación, (50), 62-79. https://doi.org/10.12795/Ambitos.2020.i50.05

Gutiérrez, D. (2011). Ernesto Laclau: El populismo y sus avatares. Universidad Central del Ecuador.

IAB (2020). Estudio Redes Sociales 2020. Disponible en: https://iabspain.es/presentacion-estudioredes-sociales-2020/

Injuve. Observatorio de la Juventud de España (2017). Jóvenes, participación y cultura política. Injuve. Disponible en: https://bit.ly/3wtTGFz

Kurtulus, S., y Ozkan, E. (2015). How do social media users in Turkey differ in terms of their use habits and preferences? International Journal of Business and Information, 10(3), pp. 337-364.

Lazer, D.M.J., Baum, M.A., Benkler, Y., Berinsky, A.J., Greenhill, K.M., Menczer, F., Metzger, M.J., Nyhan, B., Pennycook, G., Rothschild, D., Schudson, M., Sloman, S.A., Sunstein, C.R., Thorson, E.A., Watts, D.J., y Zittrain, J.L. (2018). The science of fake news. Science, 359(6380), 1094-1096. https//doi.org/10.1126/science.aao2998

Lin, K., y Lu, H. (2011). Why people use social networking sites: An empirical study integrating network externalities and motivation theory. Computers in Human Behavior, 27(3), 1152-1161. https://doi.org/10.1016/j.chb.2010.12.009 
Lin, C., Swarna, H., y Bruning, F. (2017). Taking a global view on brand post popularity: Six social media brand post practices for global markets. Business Horizons, 60(5), 621-633. https://doi.org/10.1016/j.bushor.2017.05.006

Liu, X., Shi, W., Teixeira, T., y Wedel, M. (2018). Video content marketing: The making of clips. Journal of Marketing, 82,(4), 86-101. https://doi.org/10.1509/jm.16.0048

Manzanares Triquet, J. C. (2020). Generación Z y gamificación: el dibujo pedagógico de una nueva sociedad educativa. Tejuelo 32, 263-298

Maarek, P. (1997). Marketing político y comunicación. Paidós Comunicación.

Martínez, M., y Ferraz, E. (2016). Uso de las redes sociales por los alumnos universitarios de educación: un estudio de caso de la península ibérica. Tendencias pedagógicas, 28, 33-44. https://doi.org/10.15366/tp2016.28.003

Matsa, K., y Mitchell, A. (2017). 8 Keys Takeaways about Social Media and News. 2014. Disponible en: https://pewrsr.ch/39LQ7kc

Molano, A. (1985). Los años del tropel. Fondo Editorial CEREC - CINEP y Estudios Rurales Latinoamericanos

Mudde, C., y Rovira, C. (2019). Populismo: Una breve introducción. Alianza Editorial.

Nyilasy, G. (2019). Fake news: When the dark side of persuasion takes over. International Journal of Advertising, 38(2), 336-342. https://doi.org/10.1080/02650487.2019.1586210

Pariser, Eli. (2017). El filtro burbuja: cómo la web decide lo que leemos y lo que pensamos. Barcelona: Taurus.

Papacharissi, Z., y Mendelson, A. (2011). Toward a new(er) sociability: Uses, gratifications and social capital on Facebook. En: Papathanassopoulos, S. (Ed.). Media perspectives for the 21st century. (pp. 212-230). Routledge.

Pérez Tornero, J.M., Tejedor, S., Simelio, N., y Ochoa, B. (2015). Estudiantes universitarios ante los retos formativos de las Redes Sociales: el caso de Colombia, Estudios sobre el Mensaje Periodístico, 21(1), 509-521. https://doi.org/10.5209/rev_ESMP.2015.v21.n1.49108

Piscitelli, A. (2010). El proyecto Facebook y la posuniversidad. Sistemas operativos sociales y entornos abiertos de aprendizaje. Barcelona: Ariel.

Quan-Haase, A., y Young, A. (2010). Uses and gratifications of social media: A comparison of Facebook and instant messaging. Bulletin of Science, Technology \& Society, 30(5), 350-361. https://doi.org/10.1177\%2F0270467610380009

Reyes Montes, M.C., O' Quínn Parrales, J., Morales y Gómez, J., y Rodríguez-Manzanares, E. (2011). Reflexiones sobre la comunicación política. Espacios Públicos, 14(30),85-101. https://www.redalyc.org/articulo.oa?id=67618934007 
Rodríguez-Hidalgo, C., Rivera-Rogel, D., y Romero-Rodríguez, L.M. (2020). Information Quality in Latin American Digital Native Media: Analysis Based on Structured Dimensions and Indicators. Media and Communication, 8(2), 135-145. http://dx.doi.org/10.17645/mac.v8i2.2657

Rodríguez-Rata, A. (Marzo 11, 2020). "La extrema derecha se hace con el control de TikTok, la red social de los menores". La Vanguardia. Disponible en: https://bit.ly/31QpnL2

Romero-Rodríguez, L.M., Aguaded, I., y Gadea, W. (2015). De la demonización a la polarización: un análisis desde el discurso digital del gobierno y la oposición venezolana. Argos, 32(62), $97-$ 117.

Romero-Rodríguez, L.M., y Mancinas-Chávez, R. (2016). Sobresaturación informativa: Visibilizar el mensaje institucional en tiempos de infoxicación. En L.M. Romero-Rodríguez \& R. MancinasChávez (Eds.) Comunicación Institucional y Cambio Social (pp. 111-137). Sevilla: Egregius.

Romero-Rodríguez, L.M., Contreras-Pulido, P., y Pérez-Rodríguez, M.A. (2019). Media competencies of university professors and students. Comparison of levels in Spain, Portugal, Brazil and Venezuela. Cultura y Educación, 31(2), 326-368. https://doi.org/10.1080/11356405.2019.1597564

Romero-Rodríguez, L.M., Tejedor, S., y Castillo-Abdul, B. (2021). From the Immediacy of the Cybermedia to the Need for Slow Journalism: Experiences from Ibero-America. Journalism Practice. https://doi.org/10.1080/17512786.2020.1870530

Rossi, A. (2018). ¿Burbujas de filtro?: hacia una fenomenología algorítmica. InMediaciones de la Comunicación, 13(1), 263-281. https://doi.org/10.18861/ic.2018.13.1.2836

Ruano, L., Congote, E., y Torres, A. (2016). Comunicación e interacción por el uso de dispositivos tecnológicos y redes sociales virtuales en estudiantes universitarios. RISTI: Revista Ibérica de Sistemas e Tecnologias de Información,19, 15-31. https://doi.org/10.17013/risti.19.15-31

Sadiki, L. (2018). Writing democracy: An end of author 'turn'?: From 'fake news' to 'fake democratization'. Journal of Arab \& Muslim Media Research,11(2), 113-134. https://doi.org/10.1386/jammr.11.2.113_1

Schultz, A., Wirth, W., y Müller, P. (2020). We are the People and You Are Fake News: A Social Identity Approach to Populist Citizens' False Consensus and Hostile Media Perceptions. Communication Research, 47(2), 201-226. https://doi.org/10.1177/0093650218794854

Schwarz, O. (2011). Who Moved my Conversation? Instant Messaging, Intertextuality and New Regimes of Intimacy and Truth. Media Culture Society, 33(1), 71-87. https://doi.org/10.1177/01634437-10385501

Shao, G. (2009). Understanding the appeal of user-generated media: A uses and gratification perspective. Internet Research, 19(1), 7-25.

Sharma, R., y Verma, R. (2015). Social networkers' motivation to use online social networking sites: Implications for leveraging digital marketing. International Journal of Applied Business and Economic Research, 13(5), 1159-1171. 
Sheldon, P. (2009). Maintain or develop new relationships? Gender differences in Facebook use. Rocky Mountain Communication Review, 6(1), 51-56.

Tejedor, S., Carniel-Bugs, R., y Giraldo Luque, S. (2018). Los estudiantes de Comunicación en las redes sociales: estudio comparativo entre Brasil, Colombia y España. Transinformação, 30(2), 267-276. http://dx.doi.org/10.1590/2318-08892018000200010

Turow, J. (1997). Breaking up America: Advertisers and the new media world. University of Chicago Press.

Villa Gómez, J.D., Velásquez Cuartas, N., Barrera Machado, D., y Avendaño Ramírez, M. (2020). El papel de los medios de comunicación en la fabricación de recuerdos, emociones y creencias sobre el enemigo que facilitan la polarización política y legitiman la violencia. El Ágora USB, 20(1). 1849. https://doi.org/10.21500/16578031.4642

Waisbord, S. (2020). ¿Es válido atribuir la polarización política a la comunicación digital? Sobre burbujas, plataformas y polarización afectiva. Revista SAAPl, 14(2), 249-279. https://doi.org/10.46468/rsaap.14.2.A1

Yang, S., Zhao,Y. \& Ma,Y. (2019). Analysis of the reasons and development of short video application taking Tik Tok as an example. Proceedings of the 2019 9th International Conference on Information and Social Science (pp. 12-14). https://doi.org/10.25236/iciss.2019.062

\section{AUTORES:}

\section{Luis M. Romero-Rodríguez}

Profesor del Departamento de Ciencias de la Comunicación y Sociología de la Universidad Rey Juan Carlos (Madrid, España). Doctor en Comunicación por las universidades de Huelva, Sevilla, Málaga y Cádiz (España). Premio extraordinario de Doctorado por la Universidad de Huelva. Vicepresidente del capítulo España de la Red Interuniversitaria Euroamericana de Investigación en Competencias Mediáticas para la Ciudadanía (Alfamed) y miembro del grupo de investigación Ágora (PAI-HUM648) de la Universidad de Huelva. Editor asociado de la Revista Comunicar y de la Revista Anàlisi. luis.romero@urjc.es

Índice H: 21

Orcid ID: https://orcid.org/0000-0003-3924-1517

Google Scholar: https://bit.ly/3glFUyL

ResearchGate: https://www.researchgate.net/profile/Luis-Romero-Rodriguez

Scopus ID: https://bit.ly/3iBrA6I

Academia.edu: https://urjc.academia.edu/LuisRomeroRodriguez

\section{Santiago Tejedor}

Director del Departamento de Periodismo y de Ciencias de la Comunicación de la Universidad Autónoma de Barcelona (España). Doctor en Periodismo y Ciencias de la Comunicación por la Universidad Autónoma de Barcelona, con calificación de Sobresaliente Cum Laude, y Doctor en Ingeniería de Proyectos por la Universidad Politécnica de Cataluña (UPC). Coordinador del Gabinete de Comunicación y Educación de la Universidad Autónoma de Barcelona. Subdirector del Máster Internacional de Comunicación y Educación de la Universidad Autónoma de Barcelona y Codirector del Máster en Periodismo de Viajes de la Universidad Autónoma de Barcelona. Editor de la Revista Anàlisi. 
santiago.tejedor@uab.cat

Índice H: 20

Orcid ID: https://orcid.org/0000-0002-5539-9800

Google Scholar: $\underline{\text { htps://bit.ly/3gris } 3 \mathrm{f}}$

ResearchGate: https://www.researchgate.net/profile/Santiago-Tejedor-Calvo-2

Scopus ID: $\underline{\text { htps://bit.ly/3pP5qzk }}$

Academia.edu: https://independent.academia.edu/SantiagoTejedor

\section{María Victoria Pabón Montealegre}

Directora de la Facultad de Comunicación Social-Periodismo de la Universidad Pontificia Bolivariana (Colombia). Presidenta de la Asociación Colombiana de Facultades y Programas Universitarios en Comunicación (AFACOM). Máster en Ciencias de la Información por la Universidad de Navarra (España), Especialista en Gerencia de la Comunicación Organizacional por la Universidad Pontificia Bolivariana (Colombia) y Licenciada en Comunicación Social por la Universidad Católica Andrés Bello (Venezuela). Miembro del Grupo de Investigación en Gestión de la Comunicación de la Universidad Pontificia Bolivariana (Colombia).

maria.pabon@upb.edu.co

Índice $\mathrm{H}: 3$

Orcid ID: https://orcid.org/0000-0002-1936-6358

Google Scholar: https://bit.ly/2RR8v5p 